\title{
Are smartphones really that bad? Improving the psychological measurement of technology- related behaviors
}

\author{
David A. Ellis ${ }^{1}$ \\ ${ }^{1}$ Department of Psychology, Lancaster University, Bailrigg, Lancaster, United \\ Kingdom \\ Cite as: Ellis, D. A. (2019). Are smartphones really that bad? Improving the psychological \\ measurement of technology related behaviors. Computers in Human Behavior, 97, 60-66.
}




\begin{abstract}
Understanding how people use technology remains important, particularly when measuring the impact this might have on individuals and society. To date, research within psychological science often frames new technology as problematic with overwhelmingly negative consequences. However, this paper argues that the latest generation of psychometric tools, which aim to assess smartphone usage, are unable to capture technology related experiences or behaviors. As a result, many conclusions concerning the psychological impact of technology use remain unsound. Current assessments have also failed to keep pace with new methodological developments and these data-intensive approaches challenge the notion that smartphones and related technologies are inherently problematic. The field should now consider how it might re-position itself conceptually and methodologically given that many 'addictive' technologies have long since become intertwined with daily life.
\end{abstract}


Behavioral science has spent many years attempting to understand how our interactions with technology might impact on numerous psychological outcomes (Shaw, Ellis, \& Ziegler, 2018). This lends itself to a wide variety of research questions from problematic use (e.g., do smartphones cause depression or anxiety?), to the effects of engaging with feedback as part of a behavior change intervention (e.g., does monitoring physical activity improve health?) (Ellis \& Piwek, 2018). Approaches within psychology have almost exclusively focused on correlational research that involves asking people to consider their personal experience with a technology rather than measuring their actual behavior (Ellis, Kaye, Wilcockson, \& Ryding, 2018a). This reflects a general trend within social psychology as a whole (Baumeister, Vohs, \& Funder, 2007; Doliński, 2018), but remains surprising when considered alongside automated systems (e.g., smartphones (Miller, 2012)) that can record human-computer interactions directly (Piwek, Ellis, \& Andrews, 2016). For example, behavioral interactions can be measured 'in situ' with applications. However, this is not an avenue explored by the majority of psychological research, despite having spent over a decade attempting to define 'problematic' or 'addictive' smartphone behaviors (Panova \& Carbonell, 2018). Conclusions sur- rounding use have therefore been largely negative and smartphones have repeatedly been associated with depression (Elhai, Dvorak, Levine, \& Hall, 2017), anxiety (Richardson, Hussain, \& Griffiths, 2018), disrupted sleep (Rosen, Carrier, Miller, Rokkum, \& Ruiz, 2016), cognitive impairment (Clayton, Leshner, \& Almond, 2015), and poor academic performance (Lepp, Barkley, \& Karpinski, 2015). This repeats a pattern of research priorities, which previously focused on the ne- gative impacts of many other screen-based technologies, systematically moving from television and video games, to the internet and social media (Rosen et al., 2014).

While some research has reported many beneficial effects of tech- nology use (e.g., Barr, Pennycook,
Stolz, \& Fugelsang, 2015; Przybylski \& Weinstein, 2017; Ward, Dill-Shackleford, \& Mazurek, 2018), ominous results have had a far greater impact on public opinion. This has re- cently led to a UK government enquiry concerning the effects of screen time on health (UK Parliament, 2018). However, regardless of whether research aims to focus on narrow or broad definitions of technology use, our current understanding is based around a set of popular mea- sures that present several methodological shortcomings (Shaw et al., 2018; Ryding \& Kaye, 2018). This has become particularly pertinent as methods of investigation have remained static despite exponential changes in the availability and processing power afforded by modern technology (Shaw et al., 2018).

\section{Capturing smartphone behaviors from self-report}

Historically, time has been the primary focus when attempting to quantify experiences with technology. Respondents are often asked to report their frequency or duration of use, but even simple self-reported estimates concerning mobile phone use (e.g., number of calls made, or text messages sent) have been described as 'sub-optimal' when com- pared to phone operator data (Boase \& Ling, 2013). Nevertheless, many studies continue to rely on estimates alone when making links between technology use and other psychological constructs (Butt \& Phillips, 2008). When such estimates are scaled to larger samples, these often explain very little of the variance when predicting health or subsequent behavior (Przybylski \& Weinstein, 2017; Twenge, Joiner, Rogers, \& Martin, 2018). The use of multiple technologies simultaneously (e.g., a smartphone and a laptop) also make such estimates problematic due the level of cognitive burden required to quantify many different types of automatic behavior (Boase \& Ling, 2013; Doughty, Rowland, \& Lawson, 2012; Jungselius \& Weilenmann, 2018).

Perhaps in response to this criticism, a growing number of prominent self-report instruments have been developed in an attempt to quantify smartphone related technology experiences (Fig. 1; 
Table 1). These scales, built around a conceptualization of problematic use, are often derived from previous measures that were developed to assess a specific type of technology engagement (e.g., social media or video game use). This in itself is problematic as issues associated with smartphone use may be secondary to another behavior (Panova \& Carbonell, 2018). For example, while a smartphone can be used to engage with addictive behaviors such as gambling, its use can also support and maintain a healthy lifestyle (Piwek et al., 2016).

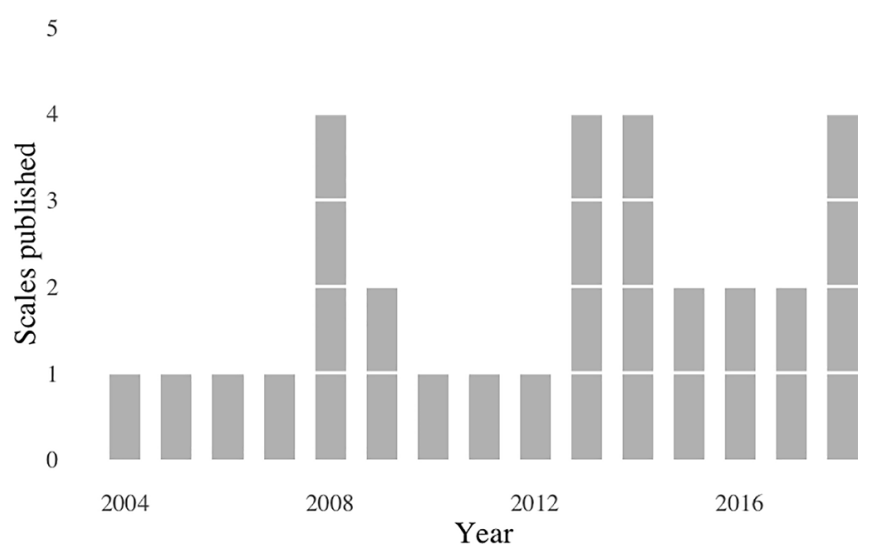

Fig. 1. Publication of self-report instruments between 2004 and 2018 (extracted from Table 1), which aim to assess a variety of constructs associated with smartphone use in the general population.

Following traditional methods associated with scale development, factor analyses ensure that tools are reliable, but their validity remains highly questionable (Table 1). While measures are framed around 'smartphone behaviors', the language used to describe subsequent results becomes misleading. Paper titles including the words 'smartphone use' are inaccurate when this has simply not been measured, causing confusion for casual readers, policy makers, and even those who work within the field (Ellis et al., 2018a). There is also little evidence to support the existence of the constructs under investigation (e.g., technology 'addiction'), yet many papers and scales continue to use language associated with a specific diagnosis (see Panova \& Carbonell, 2018 for a recent review).

These measures generally assess a respondent's attitudes and feelings towards their smartphone or technology usage. While no less important, the constructs under investigation may be fundamentally different to the very behavior they seek to explain. To date, current self- report measures do not align well with or predict simple objectively measured smartphone behaviors (Table 2 ). It would appear that objectively measured time spent on a device may correlate with some selfreport scales or duration estimates, but this relationship appears patchy. Current scales have therefore yet to demonstrate an ability to predict comparatively simple behaviors that appear to be stable within participants (Ellis et al., 2018a; Wilcockson, Ellis, \& Shaw, 2018).

Even if current measures do correlate with behavior, there is still reason to question the extent to which they measure constructs as expected. First, given the range of activities that can be performed on a smartphone, scores will have little bearing on a person's overall experience with that technology. One may speculate that active versus passive use will be an important mitigating factor when quantifying outcomes. For example, engaging in positive conversation online can bring many health benefits, with passive consumption likely to be less valuable (Day, Ong, \& Perry, 2018). Second, scales present leading questions that focus on worries surrounding a participant's relationship with their smartphone, which may be more representative of general traits. For example, measures used to assess problematic smartphone use are also likely to detect core elements of impulsivity, anxiety, or extraversion. Items that ask participants about levels of impatience associated with reduced use may instead reveal a general impulsivity that is not smartphone specific and could apply to any other personal product used on a regular basis (Belk, 2013). Indeed, how unique these results are to a specific technology and not a globalized behavior that filters into other daily activities (e.g., exercise, coffee consumption) remains unknown.

Our current understanding is therefore based around a set of measures, which will struggle to capture and understand the subsequent impact of technology. However, this has not prevented the 
development of theoretical models that are based entirely around data generated from these psychometric tools (Billieux, Maurage, LopezFernandez, Kuss, \& Griffiths, 2015). Of course, and as with any psychological phenomenon, several of these scales and the constructs they aim to measure are likely to go beyond behavior. However, the scales are routinely used without this broad conceptualization in mind and are framed as an assessment of usage alone. In recent years, these problems have become magnified further as theoretical and methodological advances have allowed for dynamic and fluid approaches to data collection. These can provide greater specificity and flexibility when exploring our relationship with technology (Jankowska, Schipperijn, \& Kerr, 2015).

\section{Objective measures of smartphone usage}

If technology use cannot be controlled experimentally, then exposure to general (e.g., hours of smartphone use) or specific use (e.g., hours of Facebook use on a device) provides an alternative source of objective data (Scharkow, 2016). This removes issues concerning socialdesirability and cognitive burden. However, while those in computer science have been measuring such interactions with smartphone technology since around 2010, these developments have had very little impact on how psychology attempts to quantify, explain, and under- stand technology use more generally (Oliver, 2010). For example, only a handful of papers have attempted to validate existing scales against behavior, with mixed results (Table 2).

These objective-based studies confirm that people use devices like smartphones and associated applications frequently and habitually (Andrews, Ellis, Shaw, \& Piwek, 2015). However, this alone does not equate to any form of problematic usage. It may seem reasonable to assume that those who spend a long time in front of a screen have problematic use, however, heavy users are not necessarily the same as problematic users (Andrews et al., 2015; Oulasvirta, Rattenbury, Ma,
\& Raita, 2012). This research also challenges the notion that mobile technology use is becoming more prevalent. For example, the quantity of short checking behaviors observed in research conducted in 2018 for example (Ellis, Davidson, Shaw, \& Geyer, 2018b) are remarkably consistent with those recorded in 2015 and 2009 (Andrews et al., 2015; Oulasvirta et al., 2012). In addition, while at a population level it would appear that smartphone use is high, within-participant patterns are consistent and establishing a true absolute baseline of typical usage for an individual appears possible (Fullwood, Quinn, Kaye, \& Redding, 2017; Wilcockson et al., 2018).

In recent years, objective studies have also started to focus on the potential negative impacts of smartphones on mood however, their conclusions are dramatically different from previous findings, which rely on self-report alone. For example, Rozgonjuk, Levine, Hall, and Elhai (2018) observed that depression and anxiety severity were not associated with total smartphone usage. In addition, higher depression scores correlated with less phone checking over a week, suggesting that periods of low-mood may lead to less engagement with technologies that primarily enable social interaction. This supports the notion that a sudden lack of smartphone use may be an early warning sign of social withdrawal (Mou, 2016). Machine learning approaches have also demonstrated that smartphone use alone does not predict negative well- being. Katevas, Arapakis, and Pielot (2018) combined an experience sampling methodology with 23 objective measures of behavior including phone unlocks, calls received, and battery drain. In one of the largest studies of its kind, participants who reported lower levels of well-being tended to use their smartphones more at night. However, this relationship was unidirectional as late-night smartphone usage was independent of low mood, which was assessed throughout the day over several weeks.

While these results and methods are compelling, they remain difficult to place in context because the majority of psychological research continues to rely on a very different methodological framework. 
They are also largely exploratory, consider a very limited definition of technology use, and remain correlational in nature. However, objective studies do appear to repeatedly challenge the notion that smartphones are problematic for a large percentage of the population. 


\section{Table 1}

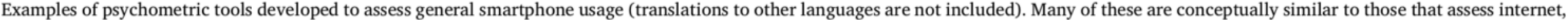

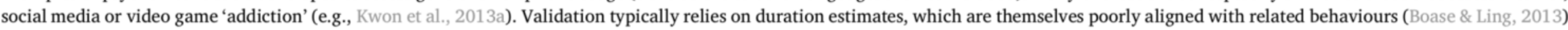

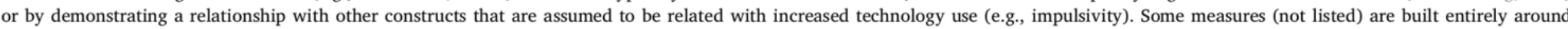

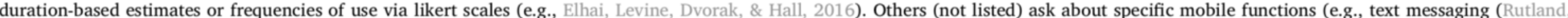

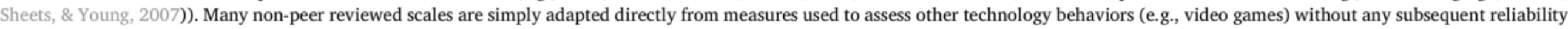
or validation checks (e.g., Hussain, Griffiths, \& Sheffield, 2017).

\begin{tabular}{|c|c|c|}
\hline Reference & Items & Scale \\
\hline Bianchi and Phillips (2005) & 27 & Mobile Phone Problem Use Scale (MPPUS) \\
\hline Billieux, Van der Linden, and Rochat (2008) & 30 & Problematic Mobile Phone Use Questionnaire (PMPUQ) \\
\hline Chóliz (2012) & 22 & Test of Mobile Phone Dependence (TMD) \\
\hline Chóliz et al. (2016) & 12 & Brief Multicultural Version of the Test of Mobile Phone Dependence Questionnaire (TMD brief) \\
\hline Csibi, Griffiths, Cook, Demetrovics, and Szabo (2018) & 6 & Smartphone Application-Based Addiction Scale (SABAS) \\
\hline Ehrenberg et al. (2008) & 3 & Mobile Phone Addictive Tendencies Scale (MPAT) \\
\hline Foerster, Roser, Schoeni, and Röösli (2015) & 10 & Mobile Phone Problem Use Scale: short version (MPPUS-10) \\
\hline Ha, Chin, Park, Ryu, and Yu (2008) & 20 & Excessive Cellular Phone Use Survey (ECPUS) \\
\hline Jenaro, Flores, Gómez-Vela, González-Gil, and Caballo (2007) & 23 & Cell Phone Overuse Scale (COS) \\
\hline Kawasaki et al. (2006) & 20 & Cellular Phone Dependence Tendency Questionnaire (CPDQ) \\
\hline Kim, Lee, Lee, Nam, and Chung (2014) & 15 & Smartphone Addiction Proneness Scale (SAPS) \\
\hline King et al. (2014) & 29 & Mobile Phone Use Questionnaire (MP-Use) \\
\hline Koo (2009) & 20 & Cell Phone Addiction Scale (CAS) \\
\hline Kuss et al. (2018) & 16 & Problematic Mobile Phone Use Questionnaire Revised (PMPUQ-R) \\
\hline Kwon et al. (2013a) & 33 & Smartphone Addiction Scale (SAS) \\
\hline Kwon, Kim, Cho, and Yang (2013b) & 10 & Smartphone Addiction Scale (SAS short version) \\
\hline Lee et al. (2017) & 28 & Smartphone Overuse Screening Questionnaire (SOS-Q) \\
\hline Leung (2008) & 17 & Mobile Phone Addiction Index (MPAI) \\
\hline Lin et al. (2014) & 26 & Smartphone Addiction Inventory (SPAI) \\
\hline Lin et al. (2017) & 10 & Smartphone Addiction Inventory: short-form (SPAI-SF) \\
\hline Lopez-Fernandez, Honrubia-Serrano, Freixa-Blanxart, and Gibson (2014) & 26 & Mobile Phone Problem Use Scale for Adolescents (MPPUSA) \\
\hline Lopez-Fernandez et al. (2018) & 15 & Short Version of the Problematic Mobile Phone Use Questionnaire (PMPUQ-SV) \\
\hline Martinotti et al. (2011) & 10 & Mobile Addiction Test (MAT) \\
\hline Marty-Dugas, Ralph, Oakman, and Smilek (2018) & 20 & Smartphone Use Questionnaires (SUQ-G \& A) \\
\hline Merlo, Stone, and Bibbey (2013) & 22 & Problematic Use of Mobile Phones Scale (PUMP) \\
\hline Rosen, Whaling, Carrier, Cheever, and Rokkum (2013) & 9 & Media and Technology Usage and Attitudes Scale (MTUAS) (smartphone items only) \\
\hline Rozgonjuk, Rosenvald, Janno, and Täht (2016) & 18 & Short version of Estonian Smartphone Addiction Proneness Scale (E-SAPS18) \\
\hline Toda, Monden, Kubo, and Morimoto (2004) & 20 & Cellular Phone Dependence Questionnaire (CPDQ) \\
\hline Walsh, White, and Young (2010) & 8 & Mobile Phone Involvement Questionnaire (MPIQ) \\
\hline Yen et al. (2009) & 12 & Problem Cellular Phone Use Questionnaire (PCPU-Q) \\
\hline Yildirim and Correia (2015) & 20 & Nomophobia Questionnaire (NMP-Q) \\
\hline
\end{tabular}


Research that attempts to develop methods, which can quantify smartphone and related technology use often aligns with a conceptual framework that problematizes usage without considering how typical these behaviors are in the general population. Conceptually, the field appears to have taken this approach with video games, the internet, and social media however, smartphones may finally be the point where psychologists consider going beyond these clinical definitions (Ellis et al., 2018a). Similarly, while psychology now has access to new technologies that would improve current practices, a number of methodological challenges also remain if new data collection methods and analytical routines are to prosper.

\subsection{Conceptual}

Conceptual misunderstandings may, in part, help drive research that focuses on the negative implications of technology, despite many obvious benefits (Days, 2018; Surrat, 1999). For example, the idea that problematic technology use can be framed as a behavioral addiction is widely accepted despite being poorly defined (Van Rooij et al., 2018). As before, the enormity of activities that can be performed on a smartphone immediately make this definition difficult (Doughty et al., 2012; Ellis et al., 2018a; Ryding \& Kaye, 2018). This has, in turn, led to the proliferation of 'treatment' programs that lack empirical support. Based on associations between reduced objective use and social withdrawal, such programs could result in unintended negative con- sequences (Stieger \& Lewetz, 2018). Of course, some forms of use could satisfy a diagnostic criterion, but the evidence base required to support such a claim has yet to appear and existing smartphone 'addiction' scales do not correlate with the rapid checking behaviors one would associate with a behavioral addiction (Andrews et al., 2015; Rozgonjuk et al., 2018). It therefore remains difficult to classify something as a behavioral addiction without actually measuring behavior. A growing body of evidence now supports the notion that psychology should start to move away from a behavioral addictions framework when studying technology use (Panova \& Carbonell, 2018).

The repeated tendency to problematize technology behaviors can also be explained by considering how little work in psychology has attempted to conceptualize technology use in a broader context. There is some overlap with models, which emphasize the formation of habits and planned behavior. Specifically, repeating a technology interaction behavior in response to a cue over time will quickly lead to the automaticity of that behavior (Lally, Van Jaarsveld, Potts, \& Wardle, 2010). Other recent attempts have considered everyday smartphone use in the context of attentional lapses and mind wandering, which are of an arguably greater concern to public health and include phone use that can demonstrably interfere with driving or walking (Ioannidou, Hermens, \& Hodgson, 2017; Marty-Dugas et al., 2018). However, other models derived from computer science, information systems, marketing, and management provide several high-level constructs that also attempt to explain impacts associated with continued use. These range widely from the measurement of individual differences to specific features of the technology under investigation (Shaw, Ellis \& Zeigler, 2018).

Perhaps before considering the impact of technology on our psychology, more resources need to be devoted to defining what we mean by usage itself. Does the use of a smartphone, for example, only register when actively creating something with the device (e.g., writing a tweet), or would this also include time spent passively viewing content (e.g. reading the news)? Current definitions of use may be too narrow, particularly when online and offline identities are intertwined. Much of the population are now permanently online (Vorderer, Krömer, \& Schneider, 2016) and smartphones have become a core part of a person's digital identity. Qualitative accounts often reflect the ability of these devices to help support existing social activities. This in part ex- plains why many people develop strong psychological attachments to them (Belk, 2013; Bodford, Kwan, 
\& Sobota, 2017; Fullwood et al., 2017; Shaw, Ellis, Kendrick, Ziegler, \& Wiseman, 2016). This 'individualized' perspective of smartphone usage fits well within the framework of the Uses and Gratifications model and reflect consistent, yet individualized patterns of behavior (Katz, Blumler, \& Gurevitch, 1974; Wilcockson et al., 2018). Therefore, people appear to often use technology in order to gratify very personal needs. However, such conceptualization is very much at odds with the majority of research, which focuses on technology as a problem, rather than a device, which supports everyday activities (Shaw et al., 2018).

\subsection{Methodological}

The use of duration estimations in isolation no longer seem suitable when contrasted directly with how people describe their usage patterns, especially when this involves multiple devices (Doughty et al., 2012). Once a technology has become intertwined with daily life, people are less able to accurately report on these behaviors, particularly when it comes to estimating the number of single interactions in a $24-\mathrm{h}$ period (Andrews et al., 2015). At the same time, research that aims to improve our understanding of technology use has become increasingly more technical, which poses a number of methodological challenges for psychologists (Piwek et al., 2016). Standard measurements produce small data sets and rarely go beyond interviews and psychometric assessment. However, smartphone applications can measure both where and how a device is being used allowing for distinctions to be made between active (e.g., typing/photo taking) or passive (e.g., reading tweets) use. It is also possible to distinguish between spontaneous use and response-based usage patterns, the latter of which involves responding to a specific notification (Piwek, Ellis \& Andrews, 2016). This leaves many new methodological avenues open to exploration whereby technology use can be assessed longitudinally (Shaw et al., 2018).

Accordingly, it is essential that results and research materials are openly available for all researchers to scrutinize and build upon. Generally, research that focuses on the effects of technology are single studies that do not engage with pre-registration or the sharing of data. Recent attempts to validate self-report measures (Table 2) also make replication very difficult (McKiernan et al., 2016). Commercial applications, for example, have not been robustly validated to ensure that they are measuring behaviors reliably, store data securely, and comply with ethical guidelines (Elhai et al., 2018; Rozgonjuk et al., 2018). On the other hand, source code, datasets, and related materials are available from Andrews et al. (2015) and Wilcockson et al. (2018). However, the smartphone framework originally used to collect data is no longer actively maintained (Piwek et al., 2016). Therefore, smart- phone applications and associated analytical tools that have been developed specifically for the purposes of research are now urgently required. Apple and Google are now providing more objective data that can be used directly by researchers, but these approaches alone will not capture the complexity of psychological processes associated with everyday technology use (Ellis et al., 2018b). An alternative, but more elaborate proposition might focus on the development or adaption of hardware attachments, which capture behaviors outside of a technology ecosystem (Liu et al., 2018). For example, small sensors which measure light can be attached to screens directly. The reverse side could simultaneously measure movement or detect a face to confirm, in addition to a measure of screen activity, if someone is actively using the device (McGrath, Scanaill, \& Nafus, 2014). 
Table 2

Research that has attempted to validate single estimates or self-report smartphone usage scales against objective behaviors.

\begin{tabular}{|c|c|c|c|}
\hline Reference & $\mathrm{N}$ & Time (days) & Findings \\
\hline Andrews et al. (2015) & 23 & 14 & $\begin{array}{l}\text { Estimated time spent using a smartphone correlated moderately with actual usage. Estimates concerning the number of times an individual used their } \\
\text { phone did not correlate with actual smartphone use. Neither estimated duration nor number of uses correlated with the Mobile Phone Problem Use } \\
\text { Scale (MPPUS). }\end{array}$ \\
\hline Elhai et al. (2018) & 68 & 7 & $\begin{array}{l}\text { No overall relationship between likert estimations of use and average daily minutes. Weak overall relationship between average daily minutes and } \\
\text { Smartphone Addiction Scale (SAS short version). Likert estimates and SAS scores predicted weekend, but not weekday averages. }\end{array}$ \\
\hline Ellis et al. (2018b) & 238 & 6 & Weak relationships observed between objective smartphone measures and a variety of self-report measures (including single duration estimates). \\
\hline Foerster et al. (2015) & 234 & * & $\begin{array}{l}\text { Weak relationships observed between short version of Mobile Phone Problem Use Scale (MPPUS-10) and phone calls/sent SMS messages. Moderate } \\
\text { correlation between MPPUS-10 and data traffic volume. "objective data was available for up to } 6 \text { months. }\end{array}$ \\
\hline Rozgonjuk et al. (2018) & 101 & 7 & $\begin{array}{l}\text { Weak relationship between Smartphone Addiction Scale (SAS) and minutes of screen time in a week (Spearman). No relationship between SAS and the } \\
\text { number of times an individual used their smartphone (Spearman). }\end{array}$ \\
\hline Lin et al. (2015) & 66 & 30 & $\begin{array}{l}\text { Estimated time spent using a smartphone correlated moderately with actual usage. Note: Duration estimates were generated with assistance from } \\
\text { psychiatrists. }\end{array}$ \\
\hline Wilcockson et al. (2018) & 27 & 14 & $\begin{array}{l}\text { No relationship observed between Mobile Phone Problem Use Scale (MPPUS) and actual usage or the number interactions with a smartphone lasting } \\
\text { less than } 15 \mathrm{~s} \text { (Spearman). }\end{array}$ \\
\hline
\end{tabular}


Results concerning the negative impact of smartphones on psycho- logical well-being may surprise rather than worry many psychologists. Smartphones are primarily used to facilitate social interactions and psychology has spent many years convincingly arguing that social support and integration has many positive health benefits (Day et al., 2018; Haslam et al., 2018; Jao, Loken, MacAndrew, Van Haitsma, \& Kolanowski, 2018; Pachucki, Ozer, Barrat, \& Cattuto, 2015). Even priming topics associated with smartphones appears to make relation- ship concepts become more accessible (Kardos, Unoka, Pléh, \& Soltész, 2018). New technology also offers a host of new possibilities to improve physical and mental health (Ellis \& Piwek, 2018). Conclusions from psychological science are therefore completely at odds with what might be expected in the general population and a new wave of research is starting to challenge previous findings (e.g., Elhai et al., 2018). Given our current understanding, one might argue that the biggest threat facing those who engage regularly with a smartphone is that these interactions take up time, which might have been traditionally spent elsewhere. For example, a lack of physical activity is of a far greater demonstrable risk to young people with previous research highlighting clear links between media exposure and childhood obesity (Chekroud et al., 2018; Lee et al., 2012; Vioque, Torres, \& Quiles, 2000).

When it comes to understanding the impact of technology more generally, there is an intrinsic lack of high-quality evidence (Ellis et al., 2018a). Revised psychometric tests may hold some value in the future, provided they are grounded in relevant theory and validated accordingly. However, psychological science should be in a position to go beyond these, particularly as social psychology appears to be acknowledging the limitations associated with a lack of behavioral measurement and validation of self-report measures across the field (Doliński, 2018). Moving forward, researchers may also wish to con- sider how behavioral data could be collected from other digital devices that can capture real-world behavior. Perhaps more importantly, a frank an open debate is required regarding how psychologists might conceptualize, measure, and understand general technology usage, which has long since become a core component of daily life (Shaw et al., 2018). 
This research did not receive any specific grant from funding agencies in the public, commercial, or not-for-profit sectors.

\section{$7 \quad$ Acknowledgements}

I would like to thank Brittany I. Davidson, Heather Shaw and Kris Geyer for their many helpful discussions in relation to this work.

\section{References}

Andrews, S., Ellis, D. A., Shaw, H., \& Piwek, L. (2015). Beyond self-report: Tools to compare estimated and real-world smartphone use. PLoS One, 10(10), e 0139004.

Barr, N., Pennycook, G., Stolz, J. A., \& Fugelsang, J. A. (2015). The brain in your pocket: Evidence that Smartphones are used to supplant thinking. Computers in Human Behavior, 48, 473-480.

Baumeister, R. F., Vohs, K. D., \& Funder, D. C. (2007). Psychology as the science of self- reports and finger movements: Whatever happened to actual behavior? Perspectives on Psychological Science, 2(4), 396-403.

Belk, R. W. (2013). Extended self in a digital world. Journal of Consumer Research, 40(3), 477500 .

Bianchi, A., \& Phillips, J. G. (2005). Psychological predictors of problem mobile phone use. CyberPsychology and Behavior, 8(1), 39-51.

Billieux, J., Maurage, P., Lopez-Fernandez, O., Kuss, D. J., \& Griffiths, M. D. (2015). Can disordered mobile phone use be considered a behavioral addiction? An update on current evidence and a comprehensive model for future research. Current Addiction Reports, 2(2), 156162.
Billieux, J., Van der Linden, M., \& Rochat, L. (2008). The role of impulsivity in actual and problematic use of the mobile phone. Applied Cognitive Psychology, 22(9), 1195-1210.

Boase, J., \& Ling, R. (2013). Measuring mobile phone use: Self-report versus log data. Journal of Computer-Mediated Communication, 18(4), 508519.

Bodford, J. E., Kwan, V. S. Y., \& Sobota, D. S. (2017). Fatal attractions: Attachment to smartphones predicts anthropomorphic beliefs and dangerous behaviors. Cyberpsychology, Behavior, and Social Networking, 20(5), 320-326.

Butt, S., \& Phillips, J. G. (2008). Personality and self reported mobile phone use. Computers in Human Behavior, 24(2), 346-360.

Chekroud, S. R., Gueorguieva, R., Zheutlin, A. B., Paulus, M., Krumholz, H. M., Krystal, J. H., et al. (2018). Association between physical exercise and mental health in 1.2 million individuals in the USA between 2011 and 2015: A cross-sectional study. The Lancet Psychiatry, 5(9), 739-746.

Chóliz, M. (2012). Mobile-phone addiction in adolescence: The test of mobile phone dependence (TMD). Progress in Health Science, 2(1), 33-44.

Chóliz, M., Pinto, L., Phansalkar, S. S., Corr, E., Mujjahid, A., Flores, C., et al. (2016). Development of a brief multicultural version of the test of mobile phone dependence (TMDbrief) questionnaire. Frontiers in Psychology, 7, 650.

Clayton, R. B., Leshner, G., \& Almond, A. (2015). The extended iSelf: The impact of iPhone separation on cognition, emotion, and physiology. Journal of Computer- Mediated Communication, 20(2), 119-135.

Csibi, S., Griffiths, M. D., Cook, B., Demetrovics, Z., \& Szabo, A. (2018). The psychometric properties of the smartphone application-based addiction scale (SABAS). International Journal of Mental Health and Addiction, 16(2), 393-403. 
Day, F. R., Ong, K. K., \& Perry, J. R. (2018). Elucidating the genetic basis of social interaction and isolation. Nature Communications, 9(1), 2457.

Days, K. T. (2018). Parents, media and panic through the years. Cham: Palgrave Pivot. Doliński, D. (2018). Is psychology still a science of behaviour? Social Psychological Bulletin, 13, e25025.

Doughty, M., Rowland, D., \& Lawson, S. (2012, July). Who is on your sofa?: TV audience communities and second screening social networks. Proceedings of the 10th European conference on interactive TV and video (pp. 7986). ACM.

Ehrenberg, A., Juckes, S., White, K. M., \& Walsh, S. P. (2008). Personality and self-esteem as predictors of young people's technology use. Cyberpsychology \& Behavior, 11(6), 739-741.

Elhai, J. D., Dvorak, R. D., Levine, J. C., \& Hall, B. J. (2017). Problematic smartphone use: A conceptual overview and systematic review of relations with anxiety and depression psychopathology. Journal of Affective Disorders, 207, 251-259.

Elhai, J. D., Levine, J. C., Dvorak, R. D., \& Hall, B. J. (2016). Fear of missing out, need for touch, anxiety and depression are related to problematic smartphone use. Computers in Human Behavior, 63, 509-516.

Elhai, J. D., Tiamiyu, M. F., Weeks, J. W., Levine, J. C., Picard, K. J., \& Hall, B. J. (2018). Depression and emotion regulation predict objective smartphone use measured over one week. Personality and Individual Differences, 133, 2128.

Ellis, D. A., Davidson, B. I., Shaw, H., \& Geyer, K. (2018b). Do smartphone usage scales predict behavior?

PsyArXiv
Ellis, D. A., Kaye, L. K., Wilcockson, T. D., \& Ryding, F. C. (2018a). Digital traces of behavior within addiction: Response to Griffiths (2017). International Journal of Mental Health and Addiction, 16(1), 240-245.

Ellis, D. A., \& Piwek, L. (2018). Failing to encourage physical activity with wearable technology: What next? Journal of the Royal Society of Medicine, 111(9), 310-313.

Foerster, M., Roser, K., Schoeni, A., \& Röösli, M. (2015). Problematic mobile phone use in adolescents: Derivation of a short scale MPPUS10. International Journal of Public Health, 60(2), 277 286.

Fullwood, C., Quinn, S., Kaye, L. K., \& Redding, C. (2017). My virtual friend: A qualitative analysis of the attitudes and experiences of smartphone users: Implications for smartphone attachment. Computers in Human Behavior, 75, 347-355.

Ha, J. H., Chin, B., Park, D. H., Ryu, S. H., \& Yu, J. (2008). Characteristics of excessive cellular phone use in Korean adolescents. CyberPsychology and Behavior, 11(6), 783-784.

Haslam, S. A., McMahon, C., Cruwys, T., Haslam, C., Jetten, J., \& Steffens, N. K. (2018). Social cure, what social cure? The propensity to underestimate the importance of social factors for health. Social Science \& Medicine, 198, 14-21.

Hussain, Z., Griffiths, M. D., \& Sheffield, D. (2017). An investigation into problematic smartphone use: The role of narcissism, anxiety, and personality factors. Journal of Behavioral Addictions, 6(3), 378-386.

Ioannidou, F., Hermens, F., \& Hodgson, T. L. (2017). Mind your step: The effects of mobile phone use on gaze behavior in stair climbing. Journal of Technology in Behavioral Science, 2(34), 109-120. 
Jankowska, M. M., Schipperijn, J., \& Kerr, J. (2015). A framework for using GPS data in physical activity and sedentary behavior studies. Exercise and Sport Sciences Reviews, 43(1), 4856.

Jao, Y. L., Loken, E., MacAndrew, M., Van Haitsma, K., \& Kolanowski, A. (2018). Association between social interaction and affect in nursing home residents with dementia. Ageing \& Mental Health, 22(6), 778-783.

Jenaro, C., Flores, N., Gómez-Vela, M., GonzálezGil, F., \& Caballo, C. (2007). Problematic internet and cell-phone use: Psychological, behavioral, and health correlates. Addiction Research and Theory, 15(3), 309-320.

Jungselius, B., \& Weilenmann, A. (2018, July). Conceptualizing 'use' in social media studies. Proceedings of the 9th international conference on social media and society (pp. 325-329). ACM.

Kardos, P., Unoka, Z., Pléh, C., \& Soltész, P. (2018). Your mobile phone indeed means your social network: Priming mobile phone activates relationship related concepts. Computers in Human Behavior, 88, 84-88.

Katevas, K., Arapakis, I., \& Pielot, M. (2018). Typical phone use habits: Intense use does not Predict negative well-being. arXiv preprint:1807.02472.

Katz, E., Blumler, J. G., \& Gurevitch, M. (1974). Utilization of mass communication by the individual. In J. G. Blumler, \& E. Katz (Eds.). The uses of mass communications: Current perspectives on gratifications research (pp. 1932). Beverly Hills, CA: SAGE.

Kawasaki, N., Tanei, S., Ogata, F., Burapadaja, S., Loetkham, C., Nakamura, T., et al. (2006). Survey on cellular phone usage on students in Thailand. Journal of Physiological Anthropology, 25(6), 377-382.
Kim, D., Lee, Y., Lee, J., Nam, J. K., \& Chung, Y. (2014). Development of Korean smartphone addiction proneness scale for youth. PLoS One, 9(5), e97920.

King, A. L. S., Valença, A. M., Silva, A. C., Sancassiani, F., Machado, S., \& Nardi, A. E. (2014). "Nomophobia": Impact of cell phone use interfering with symptoms and emotions of individuals with panic disorder compared with a control group. Clinical Practice and Epidemiology in Mental Health, 10, 28-35.

Koo, H. Y. (2009). Development of a cell phone addiction scale for Korean adolescents. Journal of Korean Academy of Nursing, 39(6), 818-828.

Kuss, D., Harkin, L., Kanjo, E., \& Billieux, J. (2018). Problematic smartphone use: Investigating contemporary experiences using a convergent design. International Journal of Environmental Research and Public Health, 15(1), 142.

Kwon, M., Kim, D. J., Cho, H., \& Yang, S. (2013b). The smartphone addiction scale: Development and validation of a short version for adolescents. PLoS One, 8(12), e83558.

Kwon, M., Lee, J. Y., Won, W. Y., Park, J. W., Min, J. A., Hahn, C., ... Kim, D. J. (2013a). Development and validation of a smartphone addiction scale (SAS). PLoS One, 8(2), e56936.

Lally, P., Van Jaarsveld, C. H., Potts, H. W., \& Wardle, J. (2010). How are habits formed: Modelling habit formation in the real world. European Journal of Social Psychology, 40(6), 998-1009.

Lee, H. K., Kim, J. H., Fava, M., Mischoulon, D., Park, J. H., Shim, E. J., ... Jeon, H. J. (2017). Development and validation study of the smartphone overuse screening questionnaire. Psychiatry Research, 257, 352-357. 
Lee, I. M., Shiroma, E. J., Lobelo, F., Puska, P., Blair, S. N., \& Katzmarzyk, P. T. Lancet Physical Activity Series Working Group. (2012). Effect of physical inactivity on major non-communicable diseases worldwide: An analysis of burden of disease and life expectancy. The Lancet, 380(9838), 219-229.

Lepp, A., Barkley, J. E., \& Karpinski, A. C. (2015). The relationship between cell phone use and academic performance in a sample of US college students. Sage Open, 5(1) 2158244015573169.

Leung, L. (2008). Linking psychological attributes to addiction and improper use of the mobile phone among adolescents in Hong Kong. Journal of Children and Media, 2(2), 93-113.

Lin, Y. H., Chang, L. R., Lee, Y. H., Tseng, H. W., Kuo, T. B., \& Chen, S. H. (2014). Development and validation of the smartphone addiction inventory (SPAI). PLoS One, 9(6), e98312.

Lin, Y. H., Lin, Y. C., Lee, Y. H., Lin, P. H., Lin, S. H., Chang, L. R., ... Kuo, T. B. (2015). Time distortion associated with smartphone addiction: Identifying smartphone ad- diction via a mobile application (App). Journal of Psychiatric Research, 65, 139-145.

Lin, Y. H., Pan, Y. C., Lin, S. H., \& Chen, S. H. (2017). Development of short-form and screening cutoff point of the Smartphone Addiction Inventory (SPAI-SF). International Journal of Methods in Psychiatric Research, 26(2), e1525.

Liu, P. T., Ruan, D. B., Yeh, X. Y., Chiu, Y. C., Zheng, G. T., \& Sze, S. M. (2018). Highly responsive blue light sensor with amorphous indium-zinc-oxide thin-film transistor based architecture. Scientific Reports, 8(1), 8153.

Lopez-Fernandez, O., Honrubia-Serrano, L., Freixa-Blanxart, M., \& Gibson, W. (2014). Prevalence of problematic mobile phone use in British adolescents. Cyberpsychology, Behavior, and Social Networking, 17(2), 91-98.
Lopez-Fernandez, O., Kuss, D. J., Pontes, H. M., Griffiths, M. D., Dawes, C., Justice, L. V., ... Gässler, A. K. (2018). Measurement invariance of the short version of the problematic mobile phone use questionnaire (PMPUQ-SV) across eight languages. International Journal of Environmental Research and Public Health, 15(6), 1213.

Martinotti, G., Villella, C., Di Thiene, D., Di Nicola, M., Bria, P., Conte, G., ... La Torre, G. (2011). Problematic mobile phone use in adolescence: A cross-sectional study. Journal of Public Health, 19(6), 545-551.

Marty-Dugas, J., Ralph, B. C. W., Oakman, J. M., \& Smilek, D. (2018). The relation be- tween smartphone use and everyday inattention. Psychology of Consciousness: Theory, Research, and Practice, 5, 46-64.

McGrath, M. J., Scanaill, C. N., \& Nafus, D. (2014). Sensor technologies: Healthcare, wellness and environmental applications. Apress.

McKiernan, E. C., Bourne, P. E., Brown, C. T., Buck, S., Kenall, A., Lin, J., ... Spies, J. R. (2016). How open science helps researchers succeed. eLife, 5 , e16800.

Merlo, L. J., Stone, A. M., \& Bibbey, A. (2013). Measuring problematic mobile phone use: Development and preliminary psychometric properties of the PUMP Scale. Journal of Addiction, 912807.

Miller, G. (2012). The smartphone psychology manifesto. Perspectives on Psychological Science, 7(3), 221-237.

Mou, D. (2016). Battling severe mental illnesses with smartphones: How patients' smartphone data can help improve clinical care. mHealth, 2, 32.

Oliver, E. (2010, June). The challenges in largescale smartphone user studies. Proceedings of the 2nd ACM international workshop on hot topics in planet-scale measurement (pp. 5). ACM. 
Oulasvirta, A., Rattenbury, T., Ma, L., \& Raita, E. (2012). Habits make smartphone use more pervasive. Personal and Ubiquitous Computing, 16(1), 105-114.

Pachucki, M. C., Ozer, E. J., Barrat, A., \& Cattuto, C. (2015). Mental health and social networks in early adolescence: A dynamic study of objectivelymeasured social interaction behaviors. Social Science \& Medicine, 125, 40-50.

Panova, T., \& Carbonell, X. (2018). Is smartphone addiction really an addiction? Journal of Behavioral Addictions, 7(2), 252-259.

Piwek, L., Ellis, D. A., \& Andrews, S. (2016). Can programming frameworks bring smartphones into the mainstream of psychological science? Frontiers in Psychology, 7, 1252.

Przybylski, A. K., \& Weinstein, N. (2017). A largescale test of the goldilocks hypothesis: Quantifying the relations between digital-screen use and the mental well-being of adolescents. Psychological Science, 28(2), 204-215.

Richardson, M., Hussain, Z., \& Griffiths, M. D. (2018). Problematic smartphone use, nature connectedness, and anxiety. Journal of Behavioral Addictions, 7(1), 109-116. Rosen, L., Carrier, L. M., Miller, A., Rokkum, J., \& Ruiz, A. (2016). Sleeping with technology: Cognitive, affective, and technology usage predictors of sleep problems among college students. Sleep Health, 2(1), 49-56.

Rosen, L. D., Lim, A. F., Felt, J., Carrier, L. M., Cheever, N. A., Lara-Ruiz, J. M., ... Rokkum, J. (2014). Media and technology use predicts illbeing among children, preteens and teenagers independent of the negative health impacts of exercise and eating habits. Computers in Human Behavior, 35, 364-375.

Rosen, L. D., Whaling, K., Carrier, L. M., Cheever, N. A., \& Rokkum, J. (2013). The media and technology usage and attitudes scale: An empirical investigation. Computers in Human Behavior, 29(6), 2501-2511.
Rozgonjuk, D., Levine, J. C., Hall, B. J., \& Elhai, J. D. (2018). The association between problematic smartphone use, depression and anxiety symptom severity, and objectively measured smartphone use over one week. Computers in Human Behavior, $87,10-17$.

Rozgonjuk, D., Rosenvald, V., Janno, S., \& Täht, K. (2016). Developing a shorter version of the Estonian smartphone addiction proneness scale (ESAPS18). Cyberpsychology. Journal of Psychosocial Research on Cyberspace, 10(4), article 4.

Rutland, J. B., Sheets, T., \& Young, T. (2007). Development of a scale to measure problem use of short message service: the SMS problem use diagnostic questionnaire. CyberPsychology and Behavior, 10(6), 841-844.

Ryding, F. C., \& Kaye, L. K. (2018). "Internet addiction": A conceptual minefield. International Journal of Mental Health and Addiction, 16(1), 225-232.

Scharkow, M. (2016). The accuracy of selfreported Internet use- a validation study using client $\log$ data. Communication Methods and Measures, 10(1), 13-27.

Shaw, H., Ellis, D. A., Kendrick, L. R., Ziegler, F., \& Wiseman, R. (2016). Predicting smartphone operating system from personality and individual differences. Cyberpsychology, Behavior, and Social Networking, 19(12), 727-732.

Shaw, H., Ellis, D. A., \& Ziegler, F. V. (2018). The Technology Integration Model (TIM). Predicting the continued use of technology. Computers in Human Behavior, 83, 204-214.

Stieger, S., \& Lewetz, D. (2018). A week without using social media: Results from an ecological momentary intervention study using smartphones. Cyberpsychology, Behavior, and Social Networking, 21(10), 618-624. 
Surrat, C. G. (1999). Netaholics?: The creation of a pathology. New York, NY: Nova Science. Toda, M., Monden, K., Kubo, K., \& Morimoto, K. (2004). Cellular phone dependence tendency of female university students. Japanese Journal of Hygiene, 59, 383-386.

Twenge, J. M., Joiner, T. E., Rogers, M. L., \& Martin, G. N. (2018). Increases in depressive symptoms, suicide-related outcomes, and suicide rates among US adolescents after 2010 and links to increased new media screen time. Clinical Psychological Science, 6(1), 3-17.

UK Parliament (2018). Science and Technology Committee: Impact of social media and screen- use on young people's health inquiry. https://www.parliament.uk/business/ committees/committees-a-z/commonsselect/science-and-technology-committee/ inquiries/parliament-2017/impact-of-socialmedia-young-people-17-19/, Accessed date: 14 August 2018.

Van Rooij, A. J., Ferguson, C. J., Colder Carras, M., Kardefelt-Winther, D., Shi, J., Aarseth, E., ... Deleuze, J. (2018). A weak scientific basis for gaming disorder: Let us err on the side of caution. Journal of Behavioral Addictions, 7(1), 1-9.

Vioque, J., Torres, A., \& Quiles, J. (2000). Time spent watching television, sleep duration and obesity in adults living in Valencia, Spain. International Journal of Obesity, 24(12), 1683.
Vorderer, P., Krömer, N., \& Schneider, F. M. (2016). Permanently online-Permanently connected: Explorations into university students' use of social media and mobile smart devices. Computers in Human Behavior, 63, 694-703.

Walsh, S. P., White, K. M., \& Young, R. M. (2010). Needing to connect: The effect of self and others on young people's involvement with their mobile phones. Australian Journal of Psychology, 62(4), 194-203.

Ward, D. M., Dill-Shackleford, K. E., \& Mazurek, M. O. (2018). Social media use and happiness in adults with autism spectrum disorder. Cyberpsychology, Behavior, and Social Networking, 21(3), 205-209.

Wilcockson, T. D. W., Ellis, D. A., \& Shaw, H. (2018). Determining typical smartphone usage: What data do we need? Cyberpsychology, Behavior, and Social Networking, 21(6), 395-398.

Yen, C. F., Tang, T. C., Yen, J. Y., Lin, H. C., Huang, C. F., Liu, S. C., et al. (2009). Symptoms of problematic cellular phone use, functional impairment and its asso- ciation with depression among adolescents in Southern Taiwan. Journal of Adolescence, 32(4), 863-873.

Yildirim, C., \& Correia, A. P. (2015). Exploring the dimensions of nomophobia: Development and validation of a self-reported questionnaire. Computers in Human Behavior, 49, 130-137. 